\title{
4-Beta-Hydroxycholesterol Measurement
}

National Cancer Institute

\section{Source}

National Cancer Institute. 4-Beta-Hydroxycholesterol Measurement. NCI Thesaurus.

Code C156514.

The determination of the amount of 4-beta-hydroxycholesterol present in a sample. 